\title{
Perfil do vento e estabilidade atmosférica próxima da superfície no Centro de Lançamento de Alcântara
}

\author{
Wind profile and near-surface atmospheric stability at the Alcântara Launch Center
}

${ }^{1}$ Diogo Nunes da Silva Ramos, ${ }^{2}$ Gilberto Fisch e ${ }^{1}$ Julio Pablo Reyes Fernandez

${ }^{1}$ Instituto Nacional de Pesquisas Espaciais , Brasil

${ }^{2}$ Instituto de Aeronáutica e Espaço, Brasil

\section{Resumo}

A natureza do vento e da estabilidade atmosférica é fundamental para as atividades de pesquisa e desenvolvimento aeroespacial do Centro de Lançamento de Alcântara, no Maranhão. Os processos físicos relacionados a esses parâmetros meteorológicos durante a estação seca são bem conhecidos, embora ainda haja uma lacuna no que diz respeito ao período chuvoso. Os dados obtidos na torre anemométrica são avaliados neste trabalho através de perfis verticais (vento e temperatura) e do número de Richardson. As características mecânicas no intervalo seco apresentam gradiente vertical reduzido entre dia e noite, indicando um efeito da brisa marítima a partir de $60 \mathrm{~m}$ de altura ao dia. Os ventos próximos da superfície são mais intensos durante a noite na estação chuvosa, cuja precipitação foi tipicamente noturna. O deslocamento dos sistemas convectivos e a ocorrência de downdrafts justificam esse comportamento. A camada superficial tende a ser neutra durante todo o ciclo diurno na época seca. Enquanto isso, essa condição de estabilidade foi observada com maior frequência durante a noite no período chuvoso. Tal padrão noturno é uma resposta aos ventos mais intensos observados durante intervalo horário nos meses chuvosos. Por ter sido um período chuvoso anômalo, com $40 \%$ de precipitação abaixo da média climatológica, esse resultado pode ter sido uma resposta a esse comportamento. Em estudos futuros, medições turbulentas serão necessárias para investigar a interação dos fluxos (i.e., energia na forma de calor, umidade e momentum) com os padrões de estabilidade atmosférica na época chuvosa.

Palavras-chave: Camada limite superficial, Número de Richardson, Gradiente vertical de temperatura potencial.

\section{Abstract}

Wind and atmospheric stability are fundamental for aerospace research and development activities at the Alcântara Launch Center, situated in the Maranhão Brazilian state. The physical processes related to these meteorological parameters during the dry season are well known. However, there is still gap concerning the rainy season. The data obtained in the anemometric tower are here studied considering vertical profiles of wind and temperature, and the Richardson bulk number. The mechanical characteristics showed weaker vertical gradient during the daytime-nighttime transition. A primary reason of that behaviour is the sea breeze from $60 \mathrm{~m}$ height of the tower. Those near-surface winds are more intense at night in the rainy season. As expected, the surface layer tends to be statically neutral throughout the daytime cycle in the dry season. Meanwhile, this stability classification was seen more frequently at the nighttime in the rainy season. Rainfall events along wet months were typically nocturnal. The deeper convective cells and its derived downdrafts help to understand this behavior. Due to -40\% precipitation anomaly reported in this rainy season, these results may have been a direct response to this condition. In future studies, turbulent measurements are required to investigate how the thermodynamic and mechanical pertubations interacts with the rainfall stability patterns during the wet season.

Keywords: Surface layer, Richardson bulk number, Lapse rate. 


\section{Introdução}

O Centro de Lançamento de Alcântara (CLA) é situado no litoral maranhense e realiza o lançamento de foguetes aeroespaciais, sendo o portal brasileiro para o espaço. Sendo assim, o conhecimento do vento e da estabilidade atmosférica é essencial para a operacionalização segura de suas atividades. Por exemplo, a dispersão dos gases oriundos da combustão dos foguetes necessita de diagnósticos eficazes da estrutura da camada limite planetária (CLP), principalmente no interior da camada limite superficial (CLS). Além disto, uma eficaz previsão do tempo também é fundamental para o resgate da carga útil dos foguetes ser realizado com sucesso através de operações militares aéreas (Fisch, 1999).

As características geográficas e meteorológicas do CLA elevam a complexidade dos problemas relacionados à CLS, como a presença das falésias que alteram o escoamento atmosférico próximo da superfície. O perfil vertical do vento possui maior intensidade e menor turbulência mecânica na época seca (julho-dezembro). No período chuvoso (janeiro-junho), esse comportamento do perfil do vento é invertido. A combinação dos ventos alísios de nordeste com a intensificação da brisa marítima descrevem os padrões dinâmicos na CLS no período seco. Entretanto, a soma do enfraquecimento da brisa com os efeitos de eventos sinóticos sobre a região do CLA (e.g., Zona de Convergência Intertropical - ZCIT e Vórtice Ciclônico de Altos Níveis - VCAN), reduzem a velocidade do vento (Fisch, 1999).

A estabilidade atmosférica da CLS está relacionada diretamente com os padrões termodinâmicos e mecânicos. Através de experimentos com túnel de vento reproduzindo as características locais de Alcântara, Loredo-Souza et al. (2004) reportaram que a condição de neutralidade atmosférica pode ser assumida para ventos $\geq 10 \mathrm{~m} \mathrm{~s}^{-1}$. A justificativa dos autores é que a elevação da mistura turbulenta causada por ventos mais intensos resulta em uma difusão mais homogênea das propriedades atmosféricas nos níveis próximos da superfície. Posteriormente, Magnago et al. (2010) confirmaram este grau de estabilidade através de observações turbulentas in situ durante o período seco. Contudo, uma avaliação conjunta destes padrões entre época seca e chuvosa ainda não foi produzido. A motivação deste estudo é comprovar se a estabilidade atmosférica também tende a neutralidade na época chuvosa. Caso esta hipótese se confirme, o direcionamento para a identificação e melhoria de simulações do vento será mais adequado.

O objetivo deste trabalho é verificar a relação da estrutura do vento e da estabilidade atmosférica na CLS de Alcântara durante dois períodos sinóticos distintos, nas épocas seca/2016 e chuvosa/2017.

\section{Dados e Métodos}

Foram usados os dados coletados na torre anemométrica de $100 \mathrm{~m}$ de altura instalada no Centro de Lançamento de Alcântara ( $2^{\circ} 19^{\prime} 8,5^{\prime \prime}$ 'S 44 $22^{\prime} 6^{\prime}$ 'O), no estado do Maranhão. Os períodos selecionados compreendem um intervalo de 30 dias referentes às estações seca (novembro/2016) e chuvosa (25/março a 24/abril de 2017). A torre possui dez níveis de medição anemométrica distribuídos entre 10 a $100 \mathrm{~m}$ de altura, igualmente espaçados em $10 \mathrm{~m}$. A temperatura do ar foram registrada nas alturas de 20,40 e $60 \mathrm{~m}$. A resolução temporal destes dados é 10 minutos. A medição dessas informações foi realizada em uma distância próxima de $600 \mathrm{~m}$ das falésias, em uma área circundada por florestas com altura média $>10 \mathrm{~m}$. Sendo assim, o nível de $10 \mathrm{~m}$ da torre foi ignorado na análise e discussão dos resultados.

As condições sinóticas atuantes durante estes períodos resultaram em uma anomalia negativa pluviométrica de até $40 \%$ entre novembro/2016 a abril/2017, segundo os informações do Centro de Previsão de Tempo e Estudos Climáticos (CPTEC) do Instituto Nacional de Pesquisas Espaciais (INPE) (disponível em <http://infoclimal. cptec. inpe.br/>). Durante a época seca, a ZCIT esteve ao norte da sua posição climatológica, resultando em ausência quase total de precipitação em Alcântara, amplitude térmica inferior a $2{ }^{\circ} \mathrm{C}$, velocidade do vento entre 5 a $15 \mathrm{~m} \mathrm{~s}^{-1}$ com direção predominante de NE. A estação chuvosa teve escoamento oscilante entre $\mathrm{E}$ a NE, com precipitação favorecida pela confluência de umidade nos baixos níveis e proximidade da ZCIT para a região. Neste período, a amplitude térmica foi de $4{ }^{\circ} \mathrm{C}$, ventos menos intensos e índices pluviométricos entre 5 a $40 \mathrm{~mm} \mathrm{~h}^{-1}$ ao longo dos dias selecionados.

\section{Diagnóstico da estabilidade atmosférica}

O perfil logaritmico do vento foi computado para os níveis de 20 a $100 \mathrm{~m}$ de altura da torre anemométrica. Em seguida, o índice de turbulência foi calculado através da razão entre o desvio padrão da velocidade do vento e a sua velocidade média o índice de turbulência $\left(\mathrm{I}=\sigma_{U} / \bar{U}\right)$. Os gradientes térmicos e mecânicos foram obtidos considerando os valores: $\mathrm{T}_{60}, \mathrm{~T}_{40}, \mathrm{U}_{100} \mathrm{e}$ $\mathrm{U}_{40}$. A estabilidade estática foi diagnosticada através do gradiente vertical de temperatura potencial $\left(\partial \theta_{v} / \partial z\right)$. O limiar de \pm $0,025 \mathrm{~K} \mathrm{~m}^{-1}$ foi adotado como condição de quase-neutralidade de $\partial \theta_{v} / \partial z$, correspondendo a uma camada superficial próxima da homogeneidade seguindo Tomasi et al. (2011). O indicativo da estabilidade entre os gradientes térmicos e mecânicos foi computado através da classificação do número de Richardson ( $R i$, Equação 1) seguindo os critérios de Sorbjan (2010): Instável $(R i<0)$; Quase-neutra $(0 \leq R i<0,02)$; Fracamente estável $(0,02 \leq R i<0,12)$; Muito estável $(0,12 \leq R i<0,7)$; e fortemente estável $(R i>0,7)$. 


$$
R i=\frac{g}{T_{v}} \frac{\Delta \theta_{v} \Delta z}{\Delta u^{2}+\Delta v^{2}}
$$

\section{Resultados e Discussões}

A figura 1 apresenta a evolução horária e diária de $U_{100}$ (figura 1a,b) e $\mathrm{T}_{60}$ (figura 1c,d) durante os períodos seco e chuvoso. A incidência de ventos $\geq 5 \mathrm{~m} \mathrm{~s}^{-1}$ é predominante em todo o período seco, principalmente durante o intervalo diurno, cuja temperatura oscila entre 27 e $29^{\circ} \mathrm{C}$. Embora a amplitude térmica seja baixa, a intensificação do vento neste período é causada pela maior magnitude da circulação da brisa marítima, que combinada com os ventos alísios de NE, dominam o escoamento atmosférico próximo da superfície. Todavia, estes padrões térmicos (figura 1d) e mecânicos (figura 1b) são modificados de forma acentuada na época chuvosa. Apesar da manutenção de ventos entre 5 e $10 \mathrm{~m} \mathrm{~s}^{-1}$, o registro de valores abaixo deste intervalo foi feito com frequência, principalmente durante e após os eventos pluviométricos. A variação de $U$ durante a passagem de eventos precipitantes é comum na região em virtude das alterações dos campos dinâmicos de escala sinótica, como a formação de correntes descendentes de ar (i.e., downdrafts). O impacto destes eventos também pode ser observado através do aumento da amplitude térmica $\left(\cong 8^{\circ} \mathrm{C}\right.$ ), como nos intervalos entre $25 /$ março e 6/abril e entre 15 e 24 /abril. Um comportamento singular de aquecimento durante 8 a 10/abril foi identificado, atigindo $29,4^{\circ} \mathrm{C}$, onde o valor máximo de $\mathrm{T}_{60}$ no período seco foi $28,8^{\circ} \mathrm{C}$.
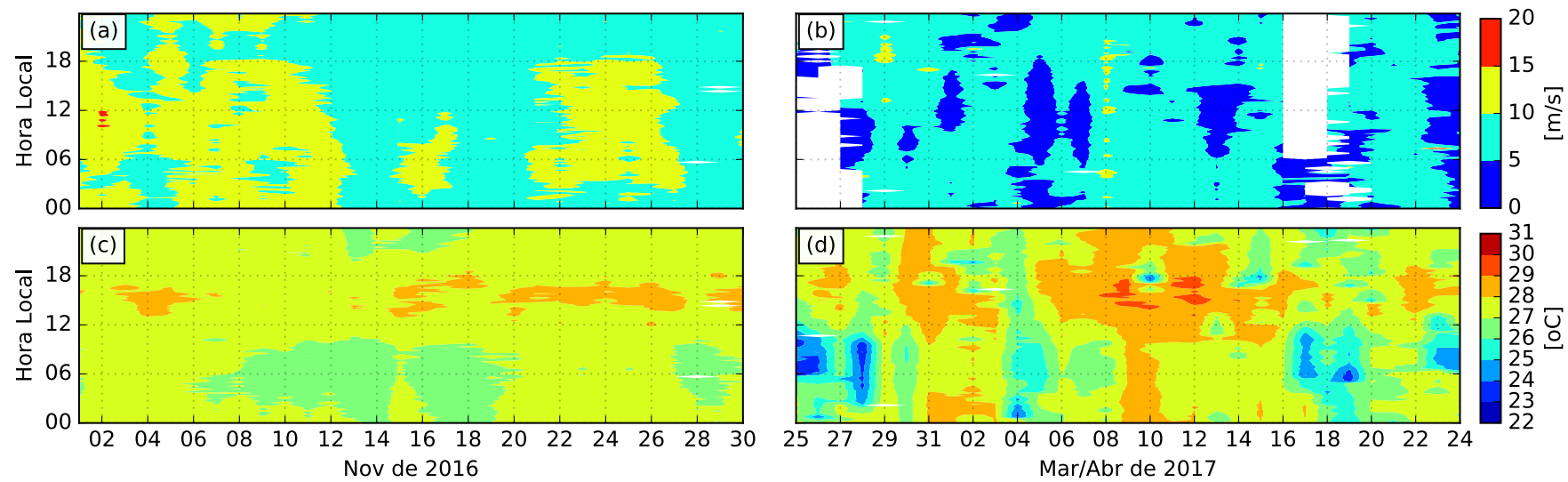

Figura 1: Evolução horária e diária de $\mathrm{U}_{100}$ (superior) e $\mathrm{T}_{60}$ (inferior) para o período seco/2016 (esquerda) e chuvoso (direita), respectivamente. A ausência de informações de $U_{100}$ esteve associada a falhas de medição ou registros anemométricos durante a ocorrência de precipitação intensa.

A variação sazonal da direção do vento entre os períodos analisados, considerando apenas intervalos diurnos e noturnos, é mostrado na figura 2. O predomínio de ventos de E a NE ocorre em ambas as estações, cuja direção ocorre quase sempre do oceano para o continente. O maior percentual de ventos $\geq 10 \mathrm{~m} \mathrm{~s}^{-1}$ na época seca acompanha a variação diária da brisa marítima da região típica desse período (Fisch, 1999), de E ao dia (figura 2a) e NE a noite (figura 2b). A variabilidade do vento causada pela passagem pelos eventos precipitantes permitiu uma maior distribuição entre as direções $\mathrm{N}$ a E, seja ao dia (figura $2 \mathrm{c}$ ) ou a noite (figura 2d).

Os padrões quase lineares nos valores médios do perfil logarítmico do vento sugerem a tendência de neutralidade, como mostra a figura 3a. Com velocidades entre 7 a $10 \mathrm{~m} \mathrm{~s}^{-1}$, os perfis do período seco são bastante similares entre dia e noite, sendo mais intensos (até $0,4 \mathrm{~m} \mathrm{~s}^{-1}$ ) durante o primeiro intervalo. No mês seco, o comportamento foi praticamente retilíneo entre 20 e $60 \mathrm{~m}$ de altura, e os ventos noturnos acima de $60 \mathrm{~m}$ indicam um ajuste mais estável que o dia. Este é um resultado esperado pois a estratificação térmica na CLP noturna é favorecida por condições de céu claro, tornando o resfriamento radiativo da superfície mais intenso que em dias nublados. O período chuvoso indica que a magnitude do vento é em torno da metade do valor médio da estação seca. Os perfis diurnos e noturnos deste período também são mais divergentes que a época seca, entre 0,3 a $0,7 \mathrm{~m} \mathrm{~s} \mathrm{~s}^{-1}$ nos níveis de 20 e $100 \mathrm{~m}$, respectivamente. Ao contrário dos valores observados no período seco, o perfil vertical noturno do intervalo chuvoso foi mais intenso que o perfil diurno. Como a precipitação noturna indica ser uma característica típica da estação chuvosa, este comportamento pode ser associado aos downdrafts ocorridos durante a passagem dos sistemas convectivos sobre o local. A incidência das correntes descendentes de ar tende a tornar o vento próximo da superfície mais intermitente, com maior turbulência dinâmica e estaticamente estável.

O índice de turbulência (figura 3 b comprova que o período chuvoso $(0,31)$ tende a ser pouco mais de $100 \%$ mais turbulento que o seco $(0,15)$. Ao fracionar estas informações em ciclo diurno e noturno, é possível confirmar que durante o dia, a turbulência é maior que a noite. No período seco (chuvoso), o intervalo diurno indicado I = 0,17 $(0,34)$, enquanto a noite esse índice é reduzido 

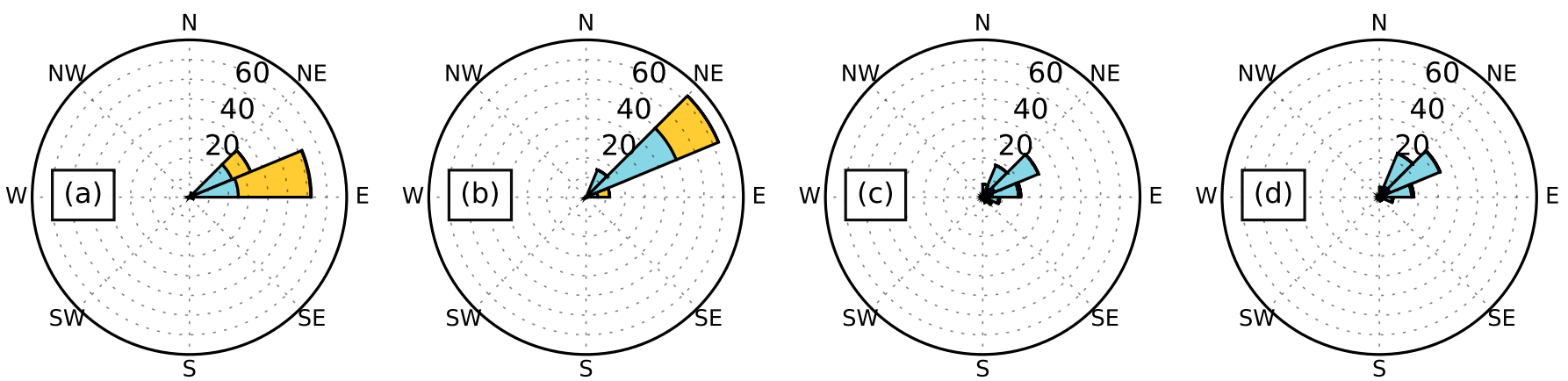

$0-5 \mathrm{~m} / \mathrm{s}$

$5-10 \mathrm{~m} / \mathrm{s}$

$10-15 \mathrm{~m} / \mathrm{s}$

$15-20 \mathrm{~m} / \mathrm{s}$

Figura 2: Rosa dos ventos nos intervalos diurnos e noturnos do período seco (a,b) e chuvoso (c,d), respectivamente.

para $0,12(0,28)$. A característica física de ventos mais intensos e menos variáveis nos dias sem precipitação da estação seca favorecem a menor turbulência dinâmica. Por outro lado, os eventos precipitantes registrados entre março-abril de 2017 alteram significativamente a amplitude dos padrões em superfície, elevando a sua intermitência.
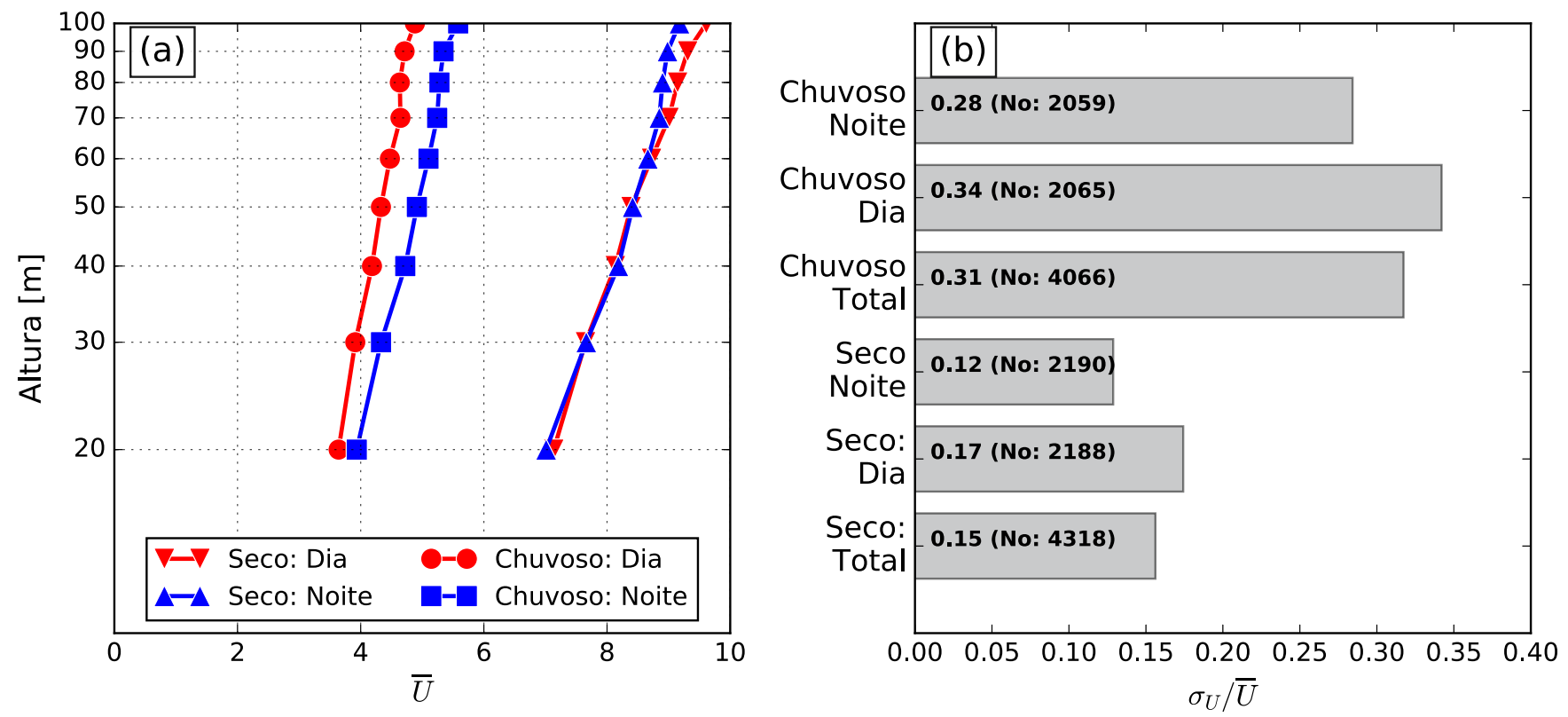

Figura 3: (a) Perfil logaritmico do vento. (b) Índice de turbulência, com o número total de amostras para cada condição.

A dispersão entre os valores da razão de $U$ entre 100 e $40 \mathrm{~m}$ com $R i$ no período seco exibida na figura 4 ressalta a predominância dos graus de estabilidade entre neutra a estável. Durante o dia neste período, aproximadamente $52 \%$ dos valores de $R i$ estão delimitados no intervalo de neutralidade, enquanto estes índices para instabilidade e estabilidade são de 5\% e 43\%, respectivamente. Como esperado, a partição destes regimes de estabilidade é desbalanceada em favorecimento da condição estável, agora próximo a $71 \%$, ao mesmo tempo que nos cenários neutros e instáveis este percentual alcançou apenas $0,1 \%$ e $29 \%$, nesta ordem. Os padrões negativos e positivos de $\Delta \theta_{v}$ correspondem corretamente aos períodos diurnos e noturnos, respectivamente (figura $4 \mathrm{~b}$ ). $\mathrm{O}$ aquecimento diurno durante a manhã é maior nos níveis menos distantes da superfície terrestre, sendo, portanto, mais quentes que os níveis acima. Durante a noite, este padrão é invertido, ou seja, a estratificação do ar próxima da superfície permite um resfriamento radiativo mais rápido que na camada mais alta da torre. Os valores de $\partial \theta_{v} / \partial z$ (figura 4 c) esteve $100 \%$ concentrado nos limites de quase neutralidade $\pm 0,025 \mathrm{~K} \mathrm{~m}^{-1}$ seja ao dia ou a noite. Esse limiar é um valor adequado para modelagem da CLP costeira em médias latitudes, pois o escoamento atosférico tende ser menos turbulentos, tornado o ar próximo da neutralidade (Tomasi et al., 2011). Todavia, esse limite deve ser diferente para zonas tropicais, onde estudos futuros podem atacar a climatologia do perfil térmico e dinâmico no interior da camada superficial através dos dados da torre.

Os comportamentos observados durante o período seco são reproduzidos de forma similar no intervalo chuvoso. A relação 
de $U_{100} / U_{40}$ com $R i$ destaca mais registros de casos instáveis na estação seca (i.e., ao dia com $12 \%$ e a noite com $4 \%$ ) que no período chuvoso (i.e., $5 \%$ ao dia e $0 \%$ durante a noite). O crescimento de casos instáveis se deve diretamente aos intervalos de ocorrência pluviométrica sobre o local, destacados na figura 4d. A característica noturna da precipitação pode justificar o aumento para $36 \%$ de neutralidade nestes horários em função dos ventos mais intensos dos downdrafts, enquanto ao dia este percentual foi de $29 \%$. Após a passagem dos sistemas precipitantes, houve intensificação de para valores superiores a $1 \mathrm{~K}$ (figura $4 \mathrm{e}$ ), por outro lado, em toda a série do período seco este valor esteve abaixo de $0,5 \mathrm{~K}$. Durante a ocorrência da precipitação, seu valor foi inferior a $0,2 \mathrm{~K}$, confirmando a homogeneidade do perfil térmico causado pelo cessamento do aquecimento da superfície. De todo modo, a exposição da camada superficial local à precipitação não causou variação significativa no lapse rate de $\theta_{v}$ (figura 4f), com percentual de 98,3 e $99 \%$ durante o dia e noite, nessa ordem.
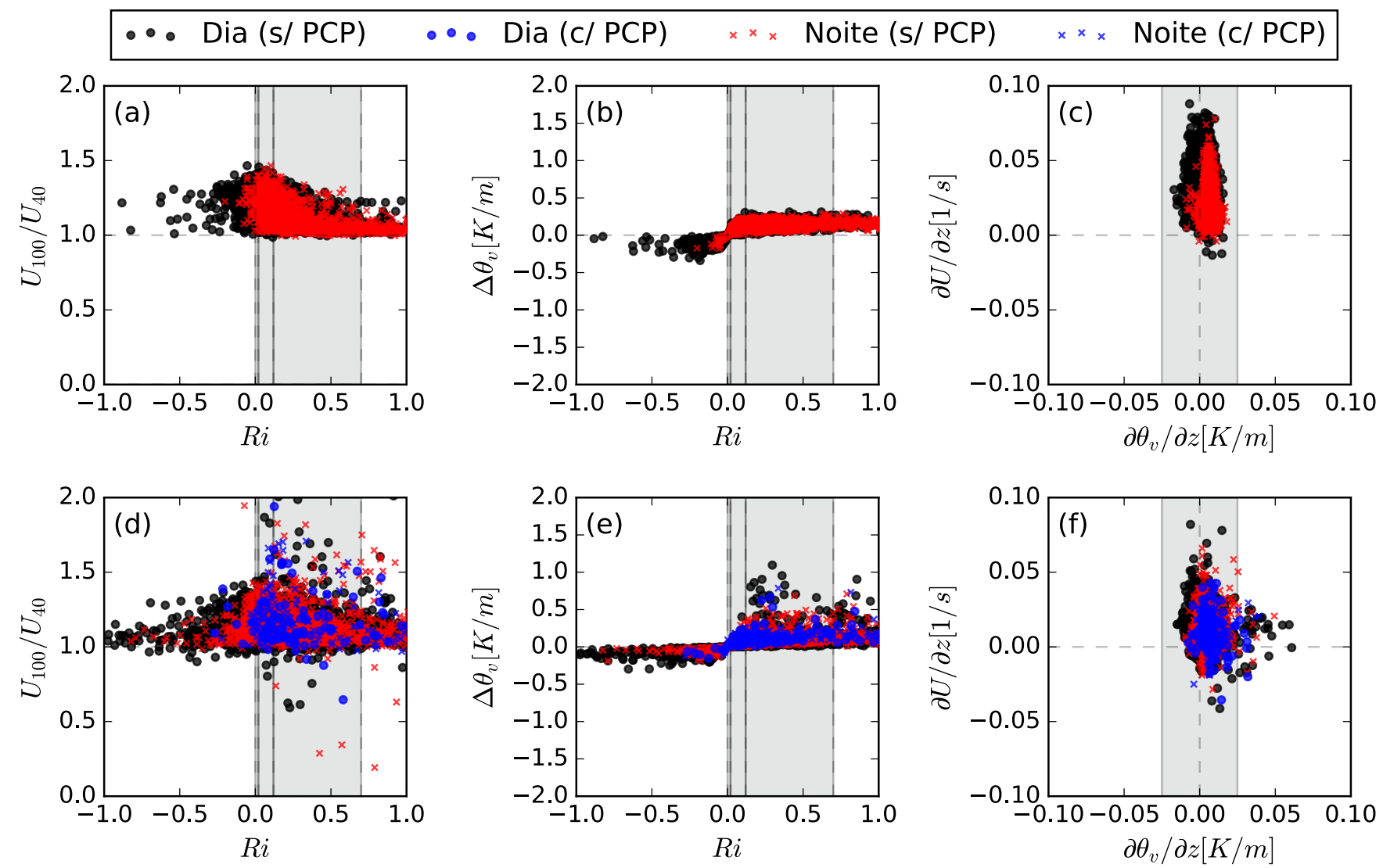

Figura 4: Razão da velocidade do vento entre os níveis de 100 e 40 m (a,d), gradiente vertical de $\theta_{v}$ entre 60 e 40 m (b,e) e perfil vertical do vento entre 100 e $40 \mathrm{~m}$ (c,f). A linha superior (inferior) corresponde aos valores diurnos e noturnos do período seco (chuvoso). As áreas em cinza indicam os intervalos de $R i$ e $\partial \theta_{v} / \partial z$ de acordo com Sorbjan (2010) e Tomasi et al. (2011), respectivamente. Os intervalos onde houve registro de precipitação são indicados pela legenda PCP.

\section{Conclusões}

Este trabalho mostrou que a estrutura espaço-temporal dos perfis térmicos e mecânicos da camada limite superficial tende a ser homogênea nos períodos seco e chuvoso de Alcântara. Entretanto, a ocorrência de eventos pluviométricos favoreceu ao aumento da amplitude térmica e variação do perfil do vento. Por outro lado, a estação chuvosa apresentou resultados análogos ao período sem precipitação. Uma provável causa deste comportamento pode ser associada à redução de chuvas de até $40 \%$ abaixo da climatologia local, tornando a CLP mais seca.

O perfil logaritmico do vento possui tendência linear em ambas as estações pluviométricas. Os perfis no período seco sugerem um desacoplamento do escoamento a partir de $60 \mathrm{~m}$ de altura. Acima deste limiar, o vento tende a ser estável e com escoamento pouco turbulento $(I \leq 0,17)$, sendo uma característica oceânica. Um outro fato observado nos resultados foi a maior velocidade do perfil do vento durante a noite na estação chuvosa. O principal aspecto para este comportamento se deve aos sistemas precipitantes (i.e., fortes correntes descendentes de ar) que atuaram com maior frequência neste intervalo horário. 
A estabilidade atmosférica próxima da superfície oscila entre os graus de quase-neutralidade a fracamente estável, principalmente na época seca. O gradiente térmico também tende a neutralidade no período chuvoso, em mais de $98 \%$ dos dados verificados, enquanto este índice é de $100 \%$ na estação sem chuvas. A classificação de Ri mostrou que a quase-neutralidade também esteve presente durante os casos chuvosos, mas com os subregimes de estabilidade estável mais frequentes, como era esperado. Em estudos futuros se faz necessário uma avaliação de medições turbulentas também durante a época chuvosa. Com isso, será possível identificar qual a contribuição vertical dos fluxos na estrutura vertical da estabilidade próxima da superfície.

\section{Referências}

Fisch, G. (1999). Características do perfil vertical do vento no Centro de Lançamento de Foguetes de Alcântara (CLA). Rev Bras Meteorol, 14(1), 11-21.

Loredo-Souza, A. M., Schettini, E. B. C., Paluch, M. J. (2004). Simulação da camada limite atmosférica em túnel de vento. Em: IV Esc. Primav. Transição e Turbulência, Associação Brasileira de Engenharia e Ciências Mecânicas (ABCM), Porto Alegre RS, p 27.

Magnago, R., Fisch, G., Moraes, O. (2010). Análise espectral do vento no Centro de Lançamento de Alcântara (CLA). Rev Bras Meteorol, 25(2), 260-269.

Sorbjan, Z. (2010). Gradient-based scales and similarity laws in the stable boundary layer. Q J R Meteorol Soc, 136(650), 1243-1254.

Tomasi, F. D., Miglietta, M. M., Perrone, M. R. (2011). The Growth of the Planetary Boundary Layer at a Coastal Site: a Case Study. Boundary-Layer Meteorol, 139(3), 521-541.

\section{Diogo Nunes da Silva Ramos}

Instituto Nacional de Pesquisas Espaciais , Brasil

Estudos Climáticos, E-mail: diogonsramos@gmail.com

Gilberto Fisch

Instituto de Aeronáutica e Espaço

Departamento de Ciência e Tecnologia Aeroespacial, Brasil, E-mail: fisch.gilberto@gmail.com

Julio Pablo Reyes Fernandez

Instituto Nacional de Pesquisas Espaciais , Brasil Estudos Climáticos, E-mail: pablo.reyes@cptec.inpe.br> 